\title{
Decomposition of dissolved DMSP and DMS in estuarine waters: dependence on temperature and substrate concentration*
}

\author{
Ronald P. Kiene, Susan K. Service \\ University of Georgia Marine Institute, Sapelo Island, Georgia 31327, USA
}

\begin{abstract}
Dimethylsulfide (DMS) is an important trace gas which is emitted from seawater to the atmosphere. DMS is believed to be derived primarily from the plant osmolyte 3-(dimethylsulfonium)propionate (DMSP). This study examined the decomposition of dissolved DMSP (DMSP diss), the production of DMS from DMSP diss, and the consumption of DMS in estuarine waters near Sapelo Island, Georgia, USA. Rate of DMSP diss disappearance from seawater was directly proportional to the concentration of $\mathrm{DMSP}_{\mathrm{diss}}$, over the range of concentrations tested $(20$ to $100 \mathrm{nM})$, and was a function of temperature; rates were very low at $4{ }^{\circ} \mathrm{C}$ and increased progressively at 16,23 and $30^{\circ} \mathrm{C}$. At $49^{\circ} \mathrm{C}$ the rate of DMSP diss metabolism was substantially lower. The production of DMS from DMSPdiss displayed similar concentration and temperature dependence. However, a mass balance of total DMSP during dark incubations indicated that $<30 \%$ of the DMSP consumed during the experiments was converted to DMS, even when chloroform $(500 \mu \mathrm{M})$ was included to prevent DMS consumption. Chloroform did not affect DMSP decomposition or DMS production from this compound. Thus, we conclude that DMS is not the major sulfur product of DMSP metabolism in estuarine waters. An alternative route for DMSP metabolism, possibly involving demethylation, is suggested. Rate of DMS consumption was directly dependent on DMS concentration and incubation temperature. DMS metabolism was strongly inhibited by chloroform $(500 \mu \mathrm{M})$ and azide $(0.25 \%)$. Results suggest that DMS production and consumption may be closely coupled in natural seawater since both these processes displayed similar concentration and temperature dependence. The characteristics (kinetic parameters) of the enzyme systems involved in DMS production and consumption are likely to play a major role in controlling the concentration of DMS in seawater
\end{abstract}

\section{INTRODUCTION}

The biogeochemical cycling of dimethyl sulfide (DMS) in seawater has come under close scrutiny in recent years because the oceans are a globally significant source of DMS to the atmosphere (Andreae 1986, 1990, Erickson 1990). The flux of DMS has important implications for the chemistry of the troposphere and, possibly, climate regulation (Bates et al. 1987, Charlson et al. 1987, Andreae 1990). Recent models of DMS cycling in seawater indicate that the distribution and concentration of DMS is governed to a significant extent by complex interactions in the food web involving phytoplankton and zooplankton, as well as bacteria, which metabolize both DMS and 3-(dimethylsul-

\footnotetext{
- Contribution no. 683 of the University of Georgia Marine Institute
}

fonium)propionate (DMSP) (Wakeham \& Dacey 1989, Kiene \& Bates 1990, Kiene unpubl.).

Seawater DMS is believed to originate from DMSP, which is an osmolyte in certain marine plants (White 1982, Reed 1983, Vairavamurthy et al. 1985, Keller et al. 1989). In the open ocean, phytoplankton appear to be the major source of DMSP and several recent studies have shown that the distribution of DMS is related to the distribution of DMSP and the phytoplankton which produce this compound (Holligan et al. 1987. Tumer et al. 1988, Iverson et al. 1989, Gibson et al. 1990). In coastal and estuarine areas, macroalgae and even rooted macrophytes such as Spartina alterniflora may also be sources of DMSP in the water column (Karsten et al. 1990, Pakulski \& Kiene unpubl.).

DMSP can be degraded via an enzymatic elimination reaction to yield DMS and acrylic acid according to the following equation (Cantoni \& Anderson 1956, Dacey \& Blough 1987): 


$$
\begin{aligned}
\left(\mathrm{CH}_{3}\right)_{2} \mathrm{~S}^{+} \mathrm{CH}_{2} \mathrm{CH}_{2} \mathrm{COO}^{-} \rightarrow & \left(\mathrm{CH}_{3}\right)_{2} \mathrm{~S}+\mathrm{CH}_{2}=\mathrm{CHCOO}^{-} \\
& +\mathrm{H}^{+}
\end{aligned}
$$

DMSP lyase activity has been found in algal extracts (Ishida 1968) and bacteria (Dacey \& Blough 1987. Kiene 1990, Ledyard \& Dacey 1990). In seawater, DMSP is found in a particulate pool (DMSP parr $_{\text {) which }}$ is presumably algae, algal grazers, fecal pellets and detritus; and in a dissolved or 'free' pool (DMSP diss ) (Turner et al. 1988, Iverson et al. 1989). The processes involved in conversion between DMSP part $_{\text {and }} \mathrm{DMSP}_{\text {diss }}$ and the production of DMS from these pools are still not well understood. However, recent studies indicate that microbial turnover of both DMSP diss and DMS occur at significant rates in seawater. These reactions are likely to be important factors which affect the concentration of DMS (Kiene \& Bates 1990, Kiene 1990 unpubl.).

The aim of the present study was to examine the decomposition of dissolved DMSP and DMS in estuarine waters near Sapelo Island, Georgia, USA. We tested whether the metabolism of both $\mathrm{DMSP}_{\text {diss }}$ and DMS was a function of the respective substrate concentrations and temperature. We also investigated the quantitative relationship between the decomposition of $\mathrm{DMSP}_{\text {diss }}$ and the production of DMS from this pool. The influences of some inhibitors on these processes were also studied.

\section{MATERIALS AND METHODS}

Sample collection. Water samples used in this study were collected at Marsh Landing Dock, located on the Duplin River, Sapelo Island ( $\left.31^{\circ} 23^{\prime} \mathrm{N}, 81^{\circ} 17^{\prime} \mathrm{W}\right)$. The Duplin River is a large tidal creek, with little direct freshwater input. Salinity in the region of sampling is generally $25 \%$, but varies between 15 and $32 \%$ depending on freshwater inputs from nearby coastal plain rivers. Water for experiments was collected directly into the incubation vessels from a small boat tied to the dock. While collecting, bottles were held several centimeters below the surface and always faced into the tidal current. Samples were immediately placed in the dark and transported to the laboratory within $10 \mathrm{~min}$.

Incubation of samples. Experiments were carried out by incubating water samples and measuring the concentrations of DMS, DMSP part and DMSP diss $_{\text {over time. }}$ Not all pools were measured in each experiment. Incubation vessels were either $250 \mathrm{ml}$ translucent Teflon (FEP) or 1 l polycarbonate bottles. All samples were incubated in the dark. With the exception of the temperature dependence experiments (see below), all samples were incubated within $2^{\circ} \mathrm{C}$ of the in situ temperature. Samples were not agitated, except during sampling, when they were gently inverted before subsample removal. All incubation vessels were acidrinsed $(10 \% \mathrm{HCl})$ and thoroughly rinsed with distilled water thereafter. The Teflon bottles were sterilized by autoclaving between experiments.

Experimental. Individual experiments were used to focus on the concentration and temperature dependence of DMSP diss and DMS metabolism as well as the effects of selected inhibitors on these processes. Inhibitors used included sodium azide $\left(\mathrm{NaN}_{3}, 0.25 \%\right.$ [w/v] final concentration), a general inhibitor of biological activity, and chloroform $\left(\mathrm{CHCl}_{3}, 500 \mu \mathrm{M}\right)$, which has been shown to inhibit DMS metabolism in oceanic waters (Kiene \& Bates 1990). Previous results indicated that this concentration of $\mathrm{CHCl}_{3}$ did not affect DMS production from DMSP (Kiene 1990). Duplicate or triplicate bottles for each treatment were used where possible. In some experiments, single sample bottles for each treatment were used because either short time courses were desired or multiple treatments were required. This was necessary because changes in DMS and DMSP occurred over relatively short time scales (minutes) and DMS must be measured immediately, with each analysis requiring 5 to $7 \mathrm{~min}$.

For the temperature dependence experiments, water samples were collected and then preincubated at the selected temperatures $\left(4,16,23,30\right.$ and $\left.49^{\circ} \mathrm{C}\right)$ for $1 \mathrm{~h}$ before additions were made and measurements begun. Separate experiments were carried out with additions of DMSP diss $(45 \mathrm{nM})$ and with DMS $(7 \mathrm{nM})$. In each experiment, controls which did not receive amendment were run at each temperature.

In further experiments, DMS and DMSP diss were added to selected samples at concentrations within the range of those observed in natural waters. DMS was added from a stock prepared in distilled water to give final added concentrations from 3 to $20 \mathrm{nM}$. DMSP was added from reagent stock solutions to give final concentrations of added $\mathrm{DMSP}_{\text {diss }}$ ranging from 10 to $80 \mathrm{nM}$. Addition volumes were always less than $100 \mu \mathrm{l}$. Measurements of the initial concentrations of sulfur compounds in the samples were made immediately after the additions to determine the actual concentration resulting from the addition (amount added + endogenous pools). A separate experiment designed to examine the quantitative relationship between DMSP decomposition and DMS production involved the addition of $40 \mathrm{nM} \mathrm{DMSP}$ diss or $500 \mu \mathrm{M} \mathrm{CHCl}$ or both.

Analytical. For analysis of DMS, a modification of the gas-stripping, cryotrapping method, used by other investigators, was employed (Andreae \& Barnard 1983, Turner et al. 1988, 1990). A $4 \mathrm{ml}$ sub-sample was withdrawn from each incubation vessel with a Teflon tube $(1.5 \mathrm{~mm}$ dia.) which was attached to a glassbarreled syringe by means of a luer fitting. The Teflon 
tube was removed from the syringe and a filter unit (Gelman), with a $2.5 \mathrm{~cm}$ glass fiber filter (Whatman $\mathrm{GF} / \mathrm{F}$ or Gelman $\mathrm{A} / \mathrm{E}, 0.7$ and $1.0 \mu \mathrm{m}$ nominal retention respectively) and an attached 22 gauge needle was connected. The volume in the syringe was carefully adjusted to $2 \mathrm{mI}$ and the sample was then introduced via a septum into the gas-stripping system.

A diagram of the gas-stripping system is shown in Fig. 1. The sparging system consisted of a silanized glass tube with a porous glass frit on which the water

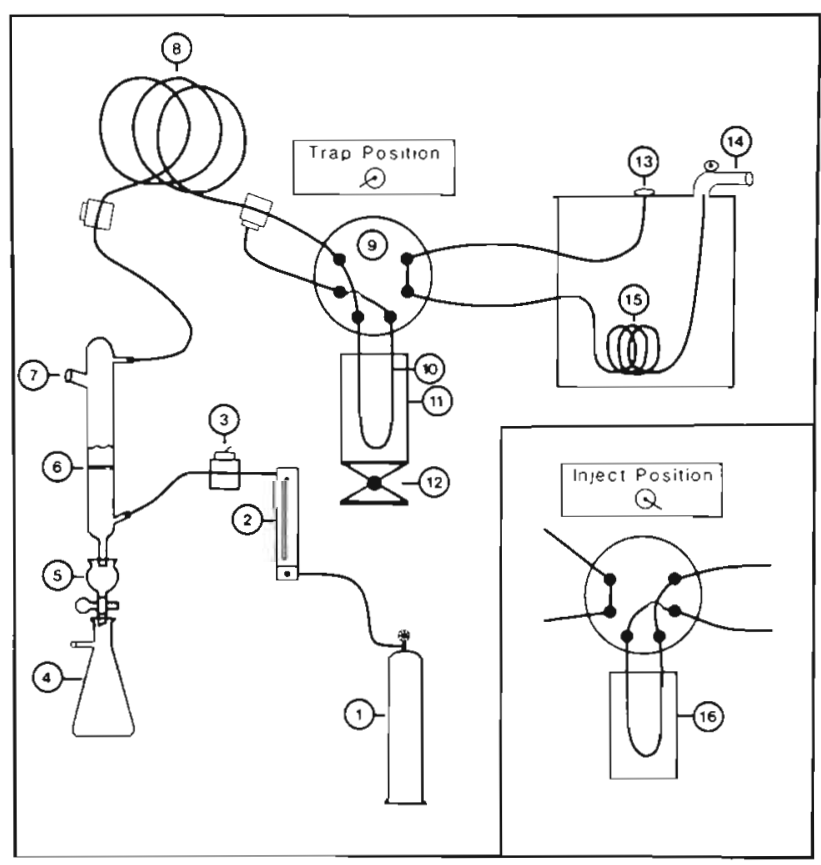

Fig. 1. Gas trapping and analysis system used in the present study. 1 , Helium sparge gas; 2 , rotometer; 3 , toggle valve; 4 , vacuum flask; 5 , Omnifit 2 -way valve; 6 , porous glass frit; 7 , crimp seal port; 8 , Nafion dryer; 9, Valco 6-port valve; 10 , sample loop of $1 / 8^{\prime \prime}(3.2 \mathrm{~mm})$ Teflon tubing; 11, dewar with liquid $\mathrm{N}_{2} ; 12$, lab jack; 13, GC injector port; 14, flame photometric detector; 15 , analytical column; 16 , dewar with hot $\left(>70^{\circ} \mathrm{C}\right)$ water

rested. The water sample was injected through a Teflon-faced septum on a side-port above the frit. The septum was held on by an aluminum crimp. Helium (ultra high purity) was used as the sparge gas and was introduced under the frit at a rate of $100 \mathrm{ml} \mathrm{min}^{-1}$. Volatile sulfur compounds were stripped from the water sample and carried with the sparge gas through a Nafion dryer (a membrane selectively permeable to water vapor; Perma-Pure, Inc, Toms River, NJ, USA) and into a 6 port stainless steel valve (Valco). With the valve in the trap position, the sample gas stream passed through a $30 \mathrm{~cm}$ long (3 mm O.D.) Teflon loop immersed in liquid nitrogen. A small amount $\left(0.2 \mathrm{~cm}^{3}\right)$ of Teflon wool was inserted in the middle of the Teflon loop to increase the surface area for gas trapping. When the sparging was completed $(2.5 \mathrm{~min})$, the valve was turned to the inject position which put the Teflon loop in line with the column in the gas chromatograph (GC). The loop was quickly placed in hot $\left(>70^{\circ} \mathrm{C}\right.$ ) water and the carrier gas from the injector port of the GC was used to sweep the sample out of the Teflon loop and into the chromatographic column.

The GC was a Shimadzu GC-9A equipped with a flame photometric detector. The column was teflon $\left(2 \mathrm{~m} \times 1 / 8^{\prime \prime}(3.2 \mathrm{~mm})\right.$ dia.) filled with Carbopack BHT100 (Supelco). The oven temperature was $100^{\circ} \mathrm{C}$ and the carrier was He at $60 \mathrm{ml} \mathrm{min}{ }^{-1}$. Under these conditions, DMS eluted with a retention time of about 0.9 min, and was adequately separated from other sulfur gases such as $\mathrm{CS}_{2}$. Peak areas were recorded with a Shimadzu CR-6A integrator. DMS standards were prepared gravimetrically in ethylene glycol as described by Andreae \& Barnard (1983). Microliter quantities of standard were injected directly into the sparging system which held $2 \mathrm{ml}$ of pre-sparged distilled water. The standard was then sparged and trapped in the same way as the samples. The square root of the peak area was a linear function of the amount of DMS injected. The minimum detectable amount of DMS ranged from 0.1 to 1 pmol per injection depending on the sensitivity of the detector, which varied during the course of the study. For typical water volumes analyzed ( $2 \mathrm{ml}$ ), this method gave detection limits for DMS of 50 to $500 \mathrm{pM}$. DMS standards prepared in glycol were compared to DMSP standards which were treated with base to give DMS (as described below). This comparison between the 2 different standards showed agreement to within $5 \%$.

Particulate and dissolved DMSP. Particulate DMSP was defined as that retained on a glass fiber filter (Whatman GF/F or Gelman A/E, nominal retention of 0.7 and $1.0 \mu \mathrm{m}$ respectively). No differences between these types of filters were observed with respect to DMSP analysis in estuarine waters. Furthermore, submicrometer particles did not appear to contribute significantly to $\mathrm{DMSP}_{\text {part }}$ since samples previously passed through glass fiber filters yielded insignificant amounts of DMSP on $0.2 \mu \mathrm{m}$ filters. Incubation vessels were gently mixed by inverting the bottles before 10 to $20 \mathrm{ml}$ was removed for analysis. The sample was filtered by gravity and the filters placed in $14 \mathrm{ml}$ serum bottles. Two $\mathrm{ml}$ of $5 \mathrm{M} \mathrm{NaOH}$ was added and the bottles quickly capped with Teflon-faced septa. The samples were then allowed to react for at least $6 \mathrm{~h}$; usually 12 to $24 \mathrm{~h}$ at $25^{\circ} \mathrm{C}$. DMSP is quantitatively and stoichiometrically decomposed in strong alkali to DMS and acrylate (White 1982, Dacey \& Blough 1987). The DMS evolved into the headspace was measured by removing a subsample of the headspace gas and injecting it 
directly into the GC column. DMSP standards were prepared by adding known amounts of DMSP to the vials and treating these exactly as the samples. Reagent DMS.HCl was obtained from Research Plus, Inc., and stock solutions were stored frozen.

Dissolved DMSP was defined as that which passed through the glass fiber filters. After the filtered water samples were sparged to remove DMS, they were pulled through the glass frit of the sparge tube into a glass side-arm flask. The sample was then poured into a small polyethylene vial and immediately frozen and stored for later analysis. For analysis, a subsample of $1 \mathrm{ml}$ was injected into the sparging tube and $1 \mathrm{ml}$ of $5 \mathrm{M} \mathrm{NaOH}$ added to produce DMS from the DMSP. The sample was sparged for $5 \mathrm{~min}$ after which time tests showed that $>95 \%$ of the DMSP was reacted. The DMS was cryotrapped and quantified as described above. Precision of the dissolved DMSP determinations for natural water samples was $7 \%$ (coefficient of variation; $\mathrm{n}=5$ ).

Statistical analyses. Rates (slopes) of consumption and production of DMS and DMSP were compared in the various experiments using SAS analysis of covariance procedures (SAS 1985). An alpha of 0.05 was used in all comparisons.

\section{RESULTS}

\section{Decomposition of $\mathrm{DMSP}_{\mathrm{diss}}$ and production of DMS}

Short-term $(<2.5 \mathrm{~h})$ incubation experiments with Duplin River water indicated that net DMS production was immediately stimulated by the addition of DMSP $_{\text {diss }}$ (Fig. 2). Accumulation of DMS occurred at the same rate whether 40,60 or $80 \mathrm{nM}$ DMSP was added ( $p>0.05$ ) (Fig. 2A). The next day a similar experiment was conducted with 20,40 and $80 \mathrm{nM}$ concentrations of added DMSP. In this case, the 20 nM DMSP treatment produced a significantly lower $(\mathrm{p}<0.05)$ DMS accumulation rate than did $40 \mathrm{nM}$, whereas accumulation with $80 \mathrm{nM}$ DMSP was only slightly higher than at $40 \mathrm{nM}$ and this result was not significant (Fig. 2B). These results suggested that the production of DMS from DMSP $_{\text {diss }}$ may have been saturated at concentrations above the $40 \mathrm{nM}$ added level. However, simultaneous removal of DMS, along with its production, could also have limited the accumulation of DMS.

A subsequent DMSP-addition experiment was carried out in which DMS metabolism was inhibited by the inclusion of chloroform $(500 \mu \mathrm{M})$ in the samples (Kiene $\&$ Bates 1990; see also below for data on the effectiveness of chloroform at preventing DMS removal). With DMS removal blocked, no apparent saturation of DMSP lyase activity was observed through the highest concentration tested (80 nM added DMSP) (Fig. 3A). The rate of DMS accumulation and the net loss rate of DMSP $_{\text {diss }}$ over the course of the incubation $(<4.5 \mathrm{~h})$ were both directly related to the initial dissolved DMSP concentration measured in the samples (22 nM endogenous + added DMSP) (Fig. 3B). Despite the presence of chloroform, which blocked the biological removal of DMS, the loss of DMSP diss $_{\text {was not balanced }}$ by the accumulation of DMS. A comparison of the slopes of the 2 curves in Fig. 3B revealed that they were significantly different $(p<0.05)$ and only about $30 \%$ of the lost DMSP was accounted for as DMS.

The quantitative relationship between changes in DMSP and DMS concentrations during incubations was investigated further (Fig. 4). In this experiment
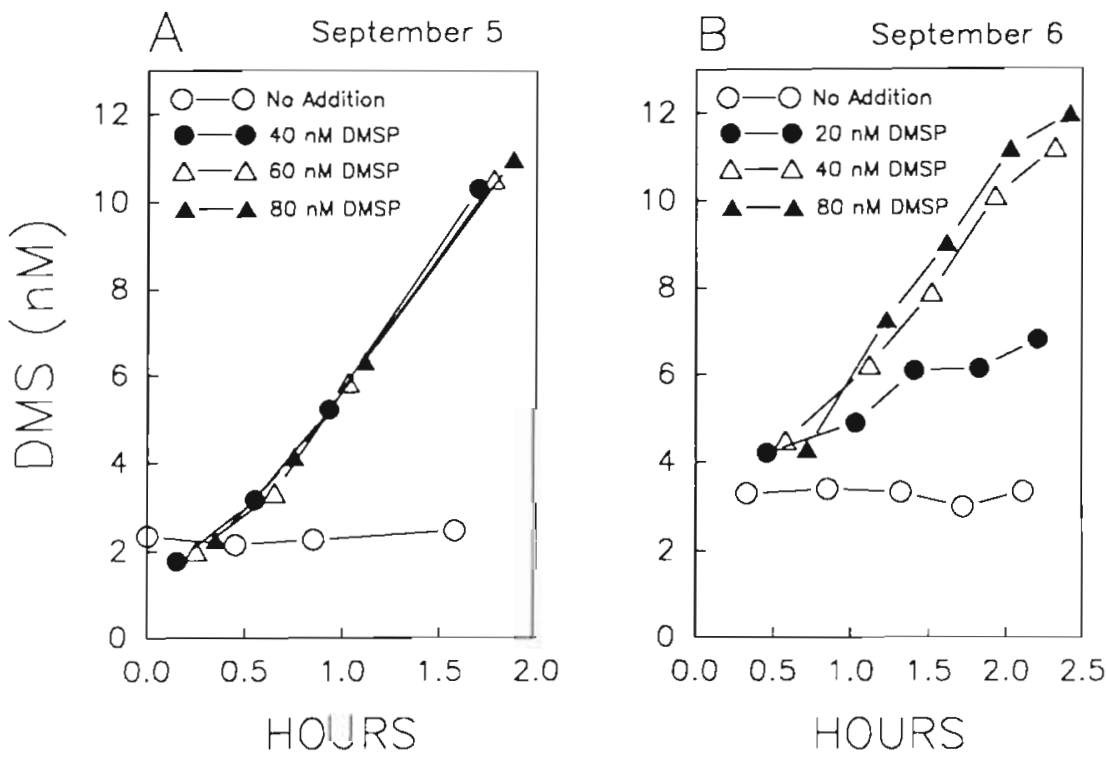

Fig. 2. Time courses of DMS concentrations in water samples treated with various levels of dissolved DMSP. Two experiments were carried out on successive days. Samples were incubated in the dark at the in situ temperature $\left(28^{\circ} \mathrm{C}\right)$. Results are from single sample bottles at each addition level 

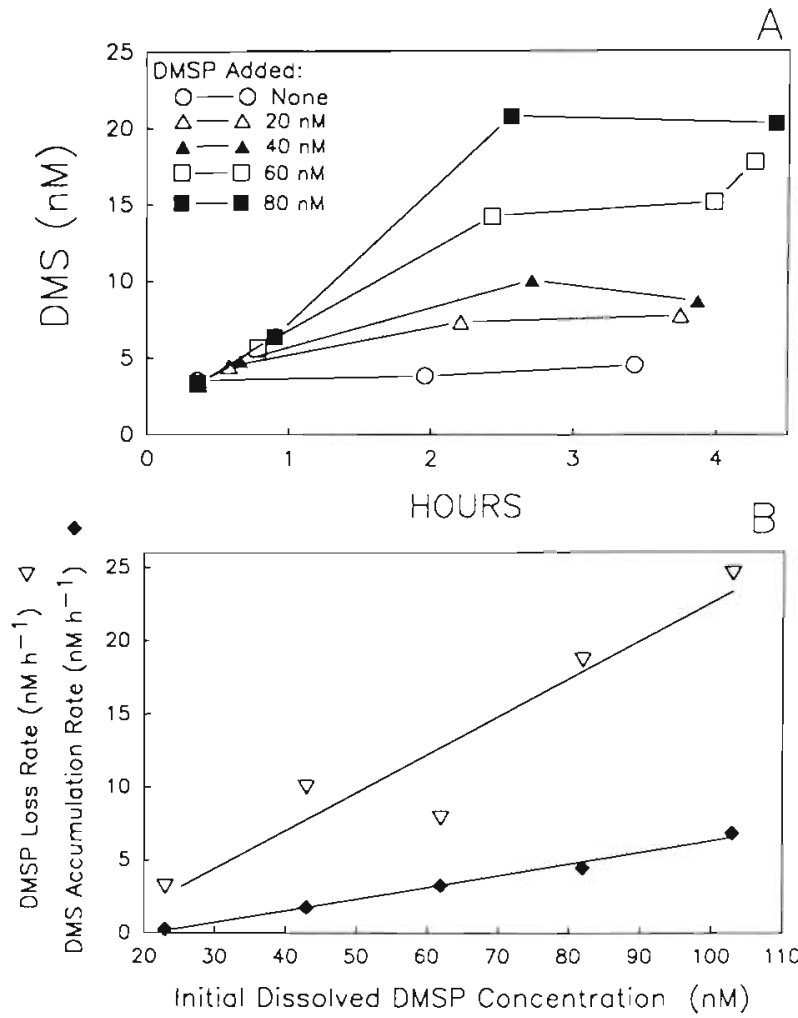

Fig. 3. (A) Time courses of DMS in water samples treated with various levels of dissolved DMSP and with $500 \mu \mathrm{M} \mathrm{CHCl}_{3}$ to inhibit DMS consumption. Samples were incubated in the dark at $28^{\circ} \mathrm{C}$. Results are from single sample bottles at each addition level. (B) Plots of DMSP loss rates and DMS accumulation rates against the initial dissolved DMSP concentration measured in the sample bottles. Rates were calculated from the linear regression of DMS production (Fig. 3A) or DMSP loss (data not shown) vs time. The least squares fits for the 2 curves are: DMSP loss $\left(n \mathrm{n} \mathrm{h}^{-1}\right)=0.26[\mathrm{nM}$ DMSP $]-3.384, \mathrm{r}^{2}$ $=0.897$; and DMS accumulation $\left(\mathrm{nM} \mathrm{h}^{-1}\right)=0.08$ [nM DMSP] $-1.648, r^{2}=0.990$ both DMSP part and DMSP diss as well as DMS were measured so that an accurate budget of these dimethyl sulfur compounds could be obtained. Particulate DMSP concentrations did not change significantly $(p>0.05)$ over the $6 \mathrm{~h}$ incubation period (Fig. 4A). Slightly higher DMSP $_{\text {part }}$ levels were seen in the DMSP diss -amended samples by the end of the experiment, however these increases were not significant. Endogenous levels of DMSP $_{\text {diss }}$ did not change significantly during the experiment (Fig. 4B), and chloroform addition had no effect on this pool $(p>0.05)$. The concentration of DMSPdiss decreased rapidly in the samples spiked with $40 \mathrm{nM}$ DMSP $_{\text {diss }}$ and this decrease was unaffected by the presence of chloroform ( $p>0.05$ ) (Fig. $4 \mathrm{~B}$ ). The endogenous pool of DMS remained unchanged (slope $=0, p$ $>0.05$ ) during the incubation (Fig. 4C), but chloroform addition caused DMS to increase at a steady rate (slope significantly greater than $0, p<0.05$ ). As expected, the DMSP-spiked samples had greater DMS production and the accumulation was greater when chloroform was present. However, the rate of increase in DMS for these 2 DMSP-treated samples was not significantly different $(p<0.05)$. The net changes in concentration which occurred in each of the dimethyl sulfur pools during the incubation are given in Table 1. For the DMSP-spiked samples, a net loss of 16 and $20 \mathrm{nM}$ total DMSP (DMSP $_{\text {part }}+$ DMSP $_{\text {diss }}=$ DMSP $_{\text {total }}$ ) occurred in the uninhibited and chloroform-inhibited samples respectively. In the uninhibited samples with DMSP added, 2.3 nM DMS accumulated, which amounted to $14 \%$ of the lost DMSP total, while those with chloroform had $5.5 \mathrm{nM}$ DMS accumulation, equivalent to $28 \%$ of the lost DMSP total.

DMSP $_{\text {diss }}$ disappeared very slowly when water samples were incubated at $4{ }^{\circ} \mathrm{C}$ (Fig. 5A), and DMS produc-
Fig. 4. Time courses of (A) particulate and (B) dissolved DMSP, and (C) DMS in water samples treated with either $\mathrm{CHCl}_{3}$ $(500 \mu \mathrm{M}), 40 \mathrm{nM} \mathrm{DMSP}_{\mathrm{d} 1 \mathrm{~s},}$, or both. Data represent the mean of duplicate bottles of each treatment with the bars indicating the range. Incubation was in the dark at $15^{\circ} \mathrm{C}$

\section{Particulate DMSP Dissolved DMSP}
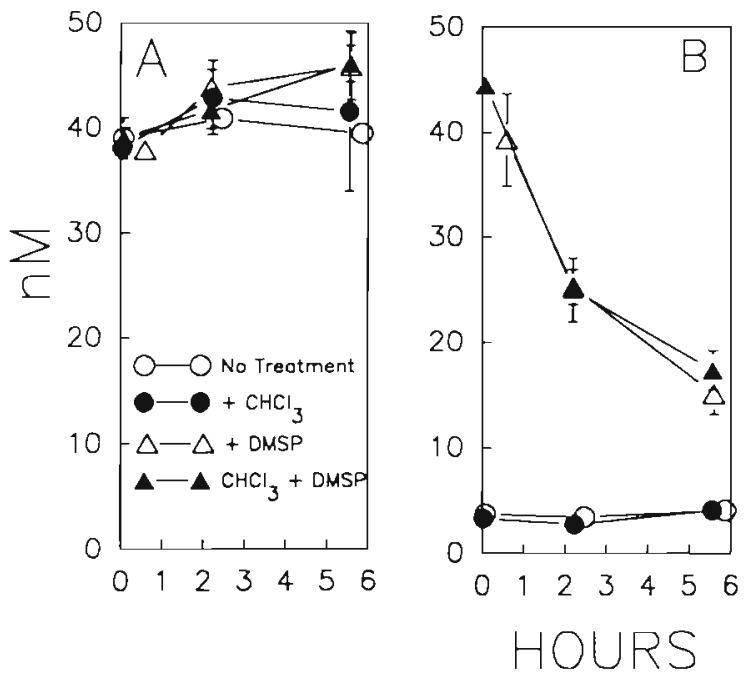

DMS

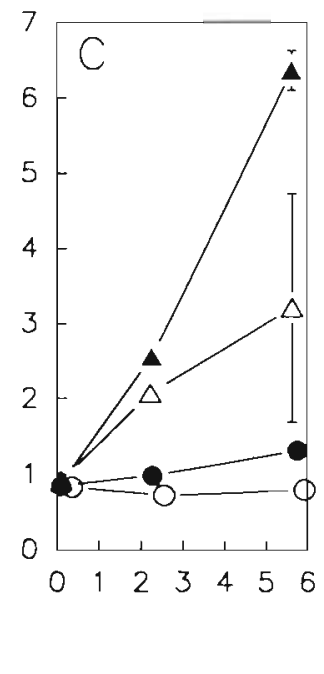


Table 1. Net changes in DMSPart DMSP diss and DMS concentration during incubations of Duplin River water with various treatments. Incubation period was $6 \mathrm{~h}$. Samples were incubated in $1 \mathrm{l}$ bottles in the dark at the in situ temperature $\left(15^{\circ} \mathrm{C}\right)$. Values represent the mean of duplicate bottles for each treatment. Data are taken from time course data in Fig. 3

\begin{tabular}{|lcccc|}
\hline Treatment & Particulate & $\begin{array}{c}\text { Net change during incubation in nmol } \text { l }^{-1} \\
\text { Dissolved } \\
\text { DMSP }\end{array}$ & $\begin{array}{c}\text { Total DMSP } \\
\text { (Diss. + Part.) }\end{array}$ \\
\hline None & 0.46 & 0.37 & 0.83 & -0.04 \\
DHCl & 3.4 & 0.79 & 0.47 \\
DMSP $(40 \mathrm{nM})$ & 8.0 & -24 & -16 & 2.3 \\
DMSP $(40 \mathrm{nM})+\mathrm{CHCl}_{3}$ & 7.0 & -27 & -20 & 5.5 \\
\hline
\end{tabular}

tion was also slow (Fig. 5B). Despite the slow rates, the changes in both these variables were significant over time (slope $\neq 0, p<0.05$ ). The rates of $D M S P_{\text {diss }}$ disappearance and DMS production at 16,23 and $30^{\circ} \mathrm{C}$ were significantly greater than at $4{ }^{\circ} \mathrm{C}$ and the rate increased progressively at these 3 temperatures. Despite the increasing trend, the rates at 16,23 and $30^{\circ} \mathrm{C}$ were not statistically different from each other. There was no significant loss of DMSP diss $_{\text {or }}$ production of DMS at
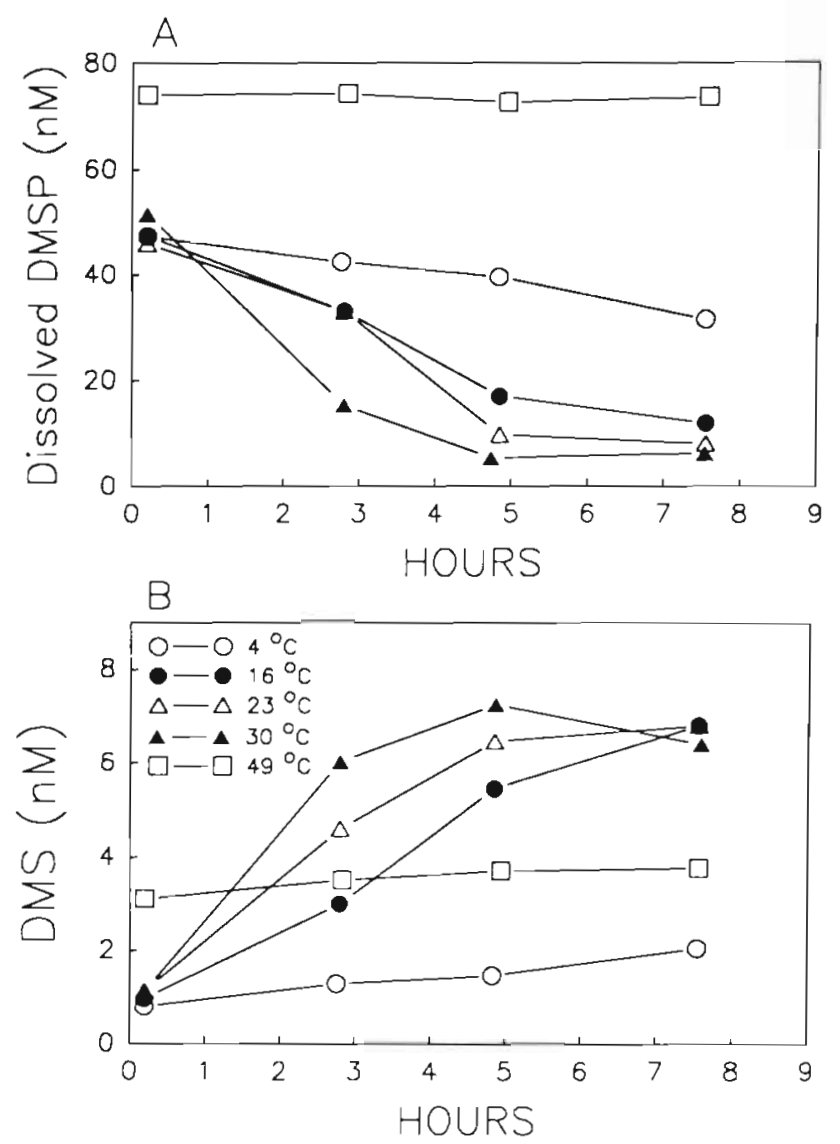

Fig. 5. Influence of temperature on (A) loss of $40 \mathrm{nM}$ added dissolved DMSP and (B) production of DMS in estuarine water. In situ temperature at the time of collection was $15^{\circ} \mathrm{C}$ $49^{\circ} \mathrm{C}(\mathrm{p}>0.05)$ (Figs. $\left.5 \& 6\right)$. Although occurring at different rates, the loss of DMSP diss and the production of DMS had similar temperature dependence (Fig. 6). Rates increased up to $30^{\circ} \mathrm{C}$, but were significantly lower at $49^{\circ} \mathrm{C}(\mathrm{p}<0.05)$. The initial DMSP diss and DMS concentrations in the $49^{\circ} \mathrm{C}$ treatment were higher than other treatments, probably due to some release of DMSP $_{\text {diss }}$ from the particulate pool and production of DMS during the $1 \mathrm{~h}$ pre-incubation period. Endogenous pools of $\mathrm{DMSP}_{\text {diss }}$ displayed similar patterns at these temperatures (data not shown), whereas endogenous DMS did not change significantly $(p>0.05)$ from the $1 \mathrm{nM}$ initial level (or $3 \mathrm{nM}$ level in the $49^{\circ} \mathrm{C}$ treatment).

\section{Consumption of DMS}

DMS was readily consumed in estuarine water samples. This activity was strongly inhibited by azide and chloroform (Figs. $7 \&$ 8). In the unspiked samples (no DMS added), both azide and chloroform caused DMS to accumulate at significantly faster rates than in uninhi-

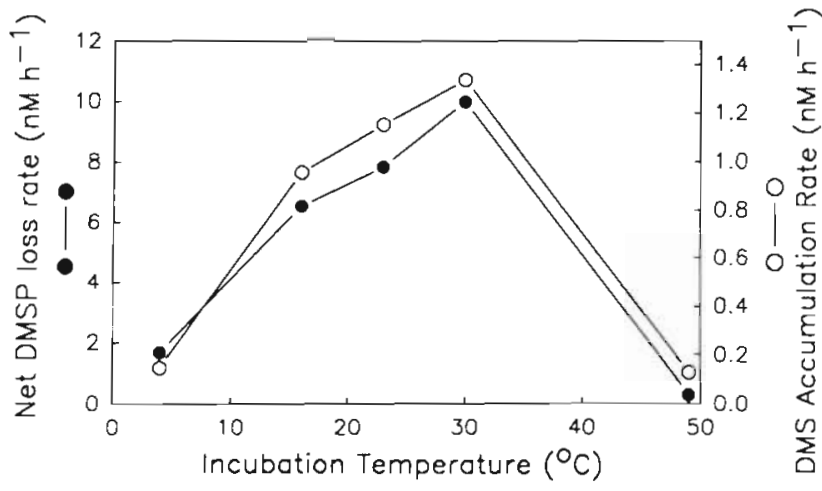

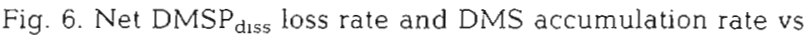
incubation temperature. Rate data were obtained from time courses in Fig. 5. Only time points from less than $5 \mathrm{~h}$ were used for the rate estimates since DMSP diss had declined to endogenous levels by that time in some treatments 
bited samples $(p<0.05)$. Net DMS consumption was at times evident from the very start of the incubation (Fig. 7), whereas in other experiments, some net production occurred during the incubation (e.g. Fig. 8). This net production was probably due to decomposition of endogenous pools of DMSP during the dark incubation.

DMS was consumed over a range of concentrations $(5$ to $20 \mathrm{nM}$ added DMS) in estuarine water (Fig. 9). In this experiment, DMS concentrations were either steady or increased slightly over the first $14 \mathrm{~h}$, and then decreased (Fig. 9A). The rate of DMS consumption over the time period 14 to $50 \mathrm{~h}$ was directly related to the concentration of the DMS concentration measured at ca $14 \mathrm{~h}$ (Fig. 9B).

The effect of incubation temperature on DMS consumption activity was investigated in a similar manner to that used to study DMSP decomposition. DMS consumption was very low at $4{ }^{\circ} \mathrm{C}$ but was progressively

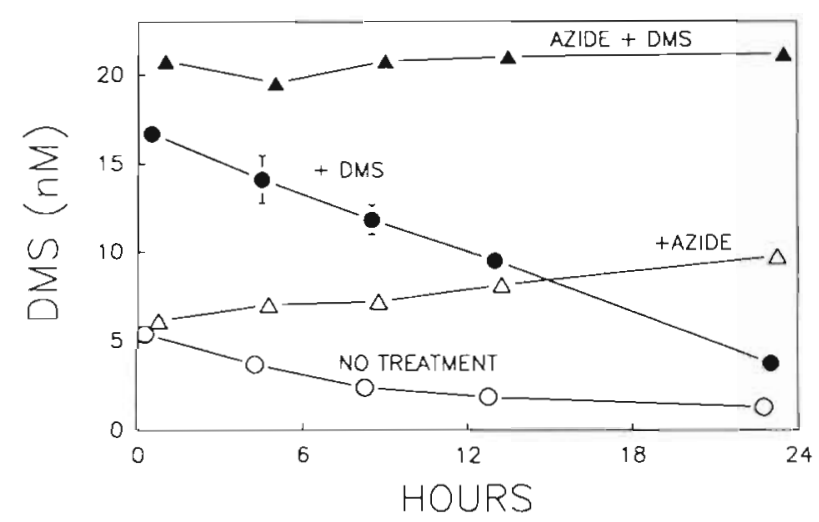

Fig. 7. Effects of azide $(0.25 \%)$ on DMS concentrations in DMS-spiked and unspiked estuarine water samples. Results are means of triplicate samples for each treatment, with bars indicating one standard deviation

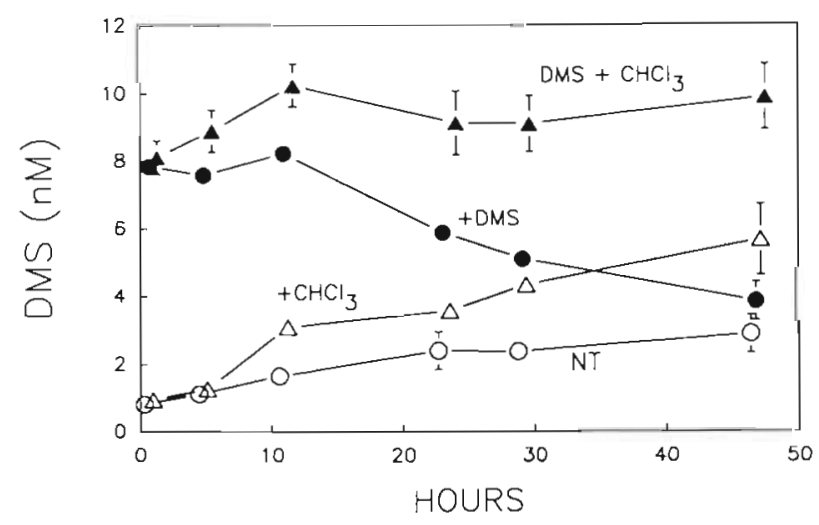

Fig. 8. Effects of chloroform $(500 \mu \mathrm{M})$ on DMS concentrations in DMS-spiked and unspiked estuarine water samples. Results are means of triplicate samples for each treatment. with bars indicating one standard deviation. NT: samples received no treatment higher at 16 and $30^{\circ} \mathrm{C}$ (Fig. 10). The rate at $23^{\circ} \mathrm{C}$ was significantly lower than at $16{ }^{\circ} \mathrm{C}(\mathrm{p}<0.05)$, but this may have been due to an addition error resulting in a lower initial DMS concentration in this treatment. At $49^{\circ} \mathrm{C}$ the rate of DMS disappearance was significantly lower than at $30^{\circ} \mathrm{C}(\mathrm{p}<0.05)$. The endogenous levels of DMS (data not shown) were about $2 \mathrm{nM}$ at the start of the experiment and declined to about $1 \mathrm{nM}$ after $24 \mathrm{~h}$ at all temperatures except $49^{\circ} \mathrm{C}$. At this temperature, DMS was about $3 \mathrm{nM}$ at the start and did not change significantly $(p>0.05)$ during the incubation.

\section{DISCUSSION}

The metabolism of DMSP and DMS are both important processes that affect the concentration of DMS in
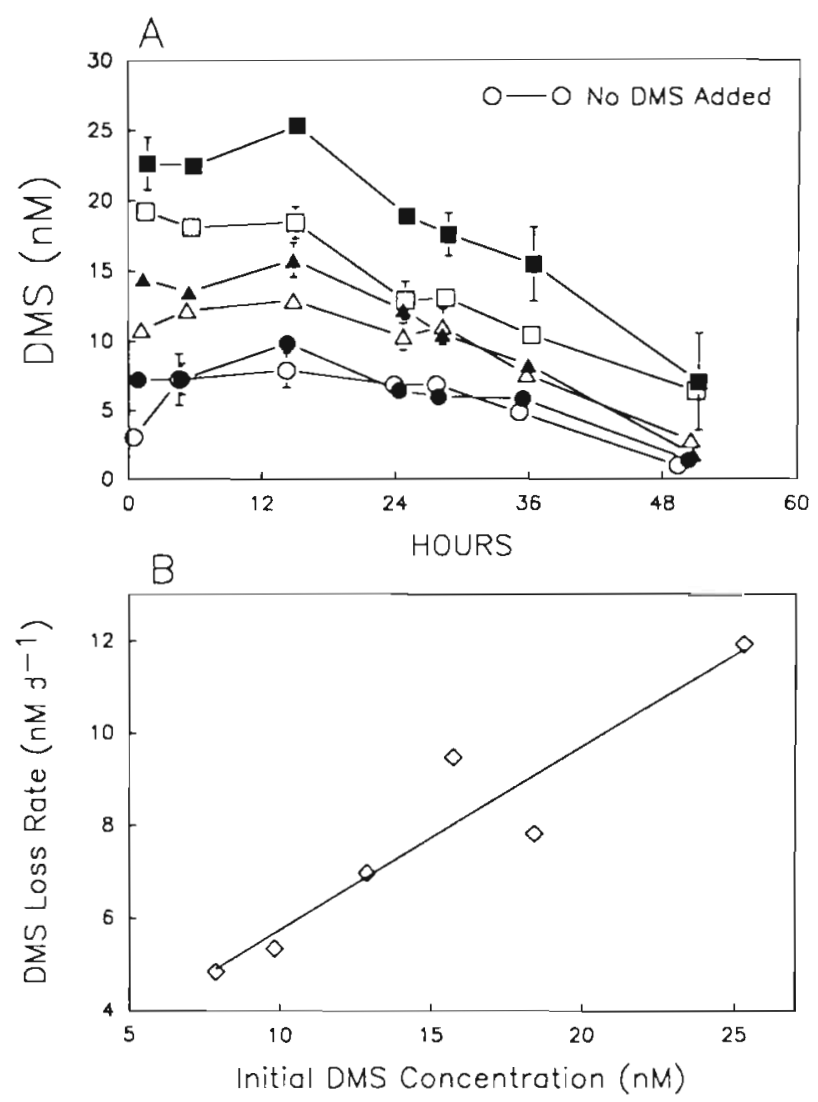

Fig. 9. (A) Time courses of DMS in water samples spiked with different levels of DMS. (O) Endogenous DMS levels; all other symbols reflect DMS added to the level shown. Incubation was in the dark at $25^{\circ} \mathrm{C}$. Data represent means of duplicate bottles for each treatment. Range of duplicates was less than $10 \%$ of mean. (B) DMS consumption rate plotted against DMS concentration measured in samples at $14 \mathrm{~h}$ (from [A]). Rates were determined by linear regression analysis of DMS concentration vs time over the period 14 to $50 \mathrm{~h}$. The least squares fit is: DMS loss rate $\left(\mathrm{nM} \mathrm{h}^{-1}\right)=0.395$ [nM DMS] +1.80 ,

$$
\mathrm{r}^{2}=0.891
$$




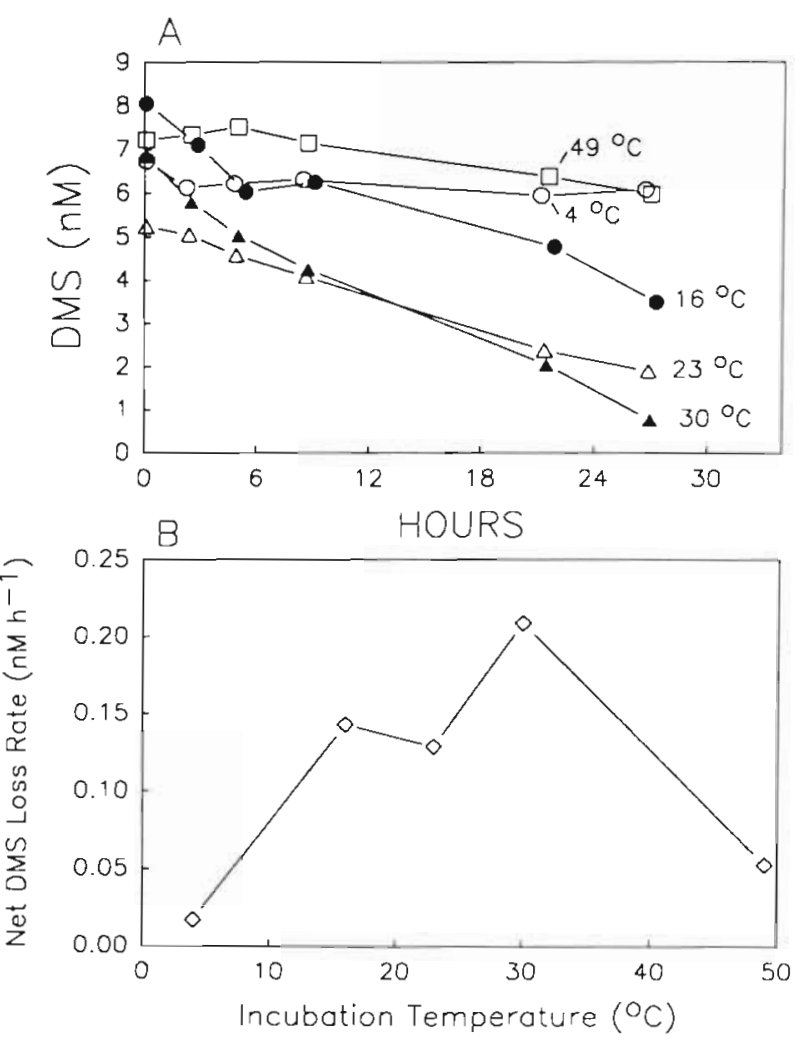

Fig. 10. (A) Effects of incubation temperature on consumption of DMS in estuarine water samples. DMS was added to these samples to give ca $7 \mathrm{nM}$ initial concentration. (Due to an error in addition, the $23^{\circ} \mathrm{C}$ treatment received only $5 \mathrm{nM}$ DMS.) Samples were incubated in the dark. Data represent single sample bottles for each treatment. In situ temperature at the time of collection was $15^{\circ} \mathrm{C}$. (B) Temperature dependence of DMS consumption rates. Rates were obtained by linear regression analysis of the time courses in (A). Samples were incubated in the dark

seawater (Kiene \& Bates 1990, Kiene unpubi.). Several recent studies have reported DMSP diss concentrations ranging from 2 to $180 \mathrm{nM}$ in estuarine, shelf and oceanic waters (Turner et al. 1988, Iverson et al. 1989, Lee \& Wakeham 1988, Kiene in press). DMS concentrations are generally lower than those of DMSP and usually fall in the range 1 to $30 \mathrm{nM}$ (Andreae \& Barnard 1984, Turner et a1. 1988). Higher DMS concentrations (up to $290 \mathrm{nM}$ ) may be found in blooms of certain DMSPproducing phytoplankton such as Phaeocystis pouchetij (Gibson et al. 1990). Bacteria which utilize DMSP and produce DMS have been isolated from seawater (Dacey \& Blough 1987, Ledyard \& Dacey 1990, Kiene 1990). However, aerobic organisms which metabolize DMS have thus far only been isolated from non-marine habitats (Suylen et al. 1986, Kanagawa \& Kelly 1986).

In this study, small ( $<50 \mathrm{nM}$ ) spikes of DMSP diss were rapidly consumed in estuarine water samples (Figs. 4 \& 5). Concentrations of DMSP diss decreased from $45 \mathrm{nM}$ to about $18 \mathrm{nM}$ in $5.5 \mathrm{~h}$ (Fig. $4 \mathrm{~B}$ ). This indicates a very high potential for DMSP diss turnover in these waters. The consumption of DMSP ${ }_{d i s s}$ is biologically mediated since it is inhibited by autoclaving and $0.2 \mu \mathrm{m}$ filtration (Kiene 1990) and displays a temperature maximum (Fig. 5). The production of DMS from DMSP diss displays similar characteristics. Unfortunately, the in situ turnover rate of DMSP in these estuarine waters is not known, and no estimates of DMSP diss turnover have been given elsewhere. The rapid consumption of the

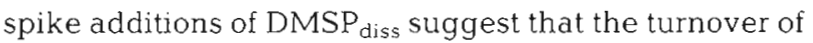
the endogenous pool must be very rapid, probably on the order of hours. This is also suggested by the fact that particulate DMSP concentrations in waters around Sapelo Island can range from 40 to $300 \mathrm{nM}$, yet at the same time, DMSP diss concentrations may only be 2 to 3 nM (R. P. Kiene unpubl.; see also Fig. 4). Either very little release of DMSP diss occurs or the turnover of the DMSP $_{\text {diss }}$ must be rapid.

The fact that the metabolism of $\mathrm{DMSP}_{\text {diss }}$ is concentration dependent (Figs. 2 \& 3) suggests that a kinetic approach could be used to estimate turnover rates. However, the plots of DMSP consumption and DMS production rates against the initial DMSP diss $_{\text {concen- }}$ tration yielded straight lines rather than the typical Michaelis-Menten type hyperbolic curves (Fig. 3). There are many possible reasons for this including the potential involvement of different enzyme systems for transport of DMSP into cells and subsequent degradation to DMS. In addition, our incubations were carried out over relatively long periods of time and the concentration of the substrate changed significantly during the incubation. Using the 4 to $6 \mathrm{~h}$ time courses we were unable to observe saturation of DMSP $_{\text {diss }}$ consumption activity even at $105 \mathrm{nM}$ DMSP $_{\text {diss }}$ concentrations (80 nM added) (Fig. 3). Since it appeared from the DMS production data in Fig. 3 that the rate of DMS production may have been similar during the very early part of the incubation in several of the higher addition levels, we attempted several short-term (<30 min) experiments with similar spikes of DMSP ${ }_{\text {diss }}$ (data not shown). Even in these cases the DMS production rate vs the added DMSP ${ }_{\mathrm{d} i s s}$ concentration (10 to $80 \mathrm{nM}$ ) did not indicate saturation of DMS production activity. Ideally, radiolabeled (preferably ${ }^{35} \mathrm{~S}$ ) DMSP would be used to determine the in situ turnover rate of DMSP diss. However, radiolabeled DMSP is not generally available and all the potential metabolic products of DMSP metabolism have not yet been identified (see below). Considerably more work will be needed to lay the groundwork for radiotracer methodology in this area.

The production of DMS from DMSP diss in estuarine waters is relatively insensitive to chemical inhibitors including chloroform (Kiene 1990). Furthermore, DMSP-utilizing bacteria are able to grow in the presence of 500 uM chloroform (Kiene 1990, Kiene 
unpubl.). Here we showed that chloroform had little or

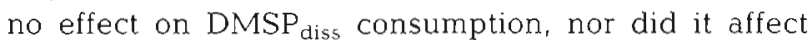
endogenous pools of DMSP diss or DMSP part (Fig. 4). Chloroform is, however, a potent inhibitor of DMS metabolism (Fig. 8; see also Kiene \& Bates 1990). This inhibitor was used to prevent DMS consumption in experiments designed to estimate how much of the DMSP degraded in water samples was converted to DMS. By measuring DMSP diss and DMSP part concentrations we could estimate the net change in total DMSP during the incubation (Table 1). When we compared the change in total DMSP concentration with the change in DMS concentration in the presence of chloroform, we found that only $28 \%$ of the lost DMSP could be accounted for by DMS production. In the absence of chloroform the production of DMS accounted for only $14 \%$ of the decrease in total DMSP. The doubling of the DMS production in the presence of chloroform suggests that about half of the total DMS produced was consumed during the incubation. Photochemical destruction of DMS (Brimblecombe \& Shooter 1986) was precluded in this experiment by incubating samples in the dark. No significant chemical losses of DMS occur during these experiments (see Fig. 7). Therefore, in addition to the familiar lyase degradation of DMSP which yields equimolar amounts of DMS and acrylate (Cantoni \& Anderson 1956), a major alternative pathway for DMSP decomposition must also occur in seawater. Similar conclusions have recently been reached for oceanic water samples (Kiene unpubl.). The observation that DMS is not the only, and perhaps not even the major, product of $\mathrm{DMSP}_{\text {diss }}$ degradation is an important finding, since it is generally assumed that DMSP production and its ultimate decomposition will lead only to DMS.

At this time we can only speculate on the nature of the alternative DMSP degradation pathway(s). Mopper \& Taylor (1986) proposed a demethylation pathway for DMSP decomposition leading to the production of 3-methiolpropionate and 3-mercaptopropionate in anoxic sediments. Kiene \& Taylor (1988) later confirmed the operation of this demethylation pathway, which occurred along with the lyase pathway in anoxic sediments. No studies of aerobic DMSP demethylation have been reported. However, Taylor \& Gilchrist (1991) have recently isolated aerobic marine bacteria which metabolize 3-methiolpropionate, an intermediate in the demethylation of DMSP. Marine bacteria that demethylate compounds which are structurally similar to DMSP, such as glycine betaine, have been isolated previously (Shieh 1966). Thus, it appears reasonable to speculate that demethylation may be responsible for removing $\mathrm{DMSP}_{\text {diss }}$ from seawater. Other possibilities for DMSP removal include potential chemical demethylation by reaction with iodide, as proposed by White
(1982) and Brinkman et al. (1985). However, this is not likely to be a major removal mechanism for DMSP $\mathrm{d}_{\mathrm{d} s \mathrm{~s}}$ because removal is inhibited at the relatively mild temperature of $49^{\circ} \mathrm{C}$ (Fig. 5). Most chemical reactions would be expected to proceed faster at higher temperatures.

The DMS formed from DMSP may accumulate or it may be consumed by biological activity. DMS consumption was clearly biological since it was inhibited by azide and chloroform and it displayed a temperature maximum between 30 and $49^{\circ} \mathrm{C}$ (Figs. 7, $8 \& 10$ ). DMS consumption rates increased at higher DMS concentrations (Fig. 9). The time course data in Fig. 9 show that DMS concentrations held steady or increased for the first $14 \mathrm{~h}$ of incubation, and declined thereafter. The initial steady or increasing concentration does not necessarily indicate a lag in DMS utilization, but rather a period of no net consumption. Some DMS is undoubtedly produced during the incubations from the endogenous pools of DMSP part and DMSP diss (these were not measured in this experiment). DMS production may balance or exceed consumption during certain periods. The time course behavior of DMS during bottle incubations is highly dependent on the characteristics of the water parcel sampled and the biological community within it. A variety of patterns for DMS vs time, including immediate increases, immediate decreases or no net change have been observed in estuarine and oceanic waters (Kiene unpubl.). These patterns reflect the dynamics of DMSP $_{\text {part }}$, DMSP diss, and DMS.

In Fig. 9, the DMS concentrations at $14 \mathrm{~h}$ were used to plot the rate of DMS consumption against DMS concentration. This plot yielded a straight line over the range of 7 to $26 \mathrm{nM}$ DMS (Fig. 9). As with the results from DMSP $\mathrm{d}_{15 s}$ spike additions, discussed earlier, these results may not fit enzyme kinetic models because of the long incubation periods and constantly changing substrate concentrations. The rates of DMS consumption determined from the DMS addition experiments are similar to those obtained by Kiene \& Bates (1990) using a chloroform inhibition technique with waters having 5 to $15 \mathrm{nM}$ DMS concentrations.

Several recent studies suggested that DMS removal by biological mechanisms may be a very important factor controlling the concentration of DMS in seawater (Wakeham et al. 1987, Leck et al. 1990, Kiene \& Bates 1990, Kiene unpubl.). The results presented here provide further evidence for this. In addition, our results suggest that the production and consumption of DMS may be closely coupled in estuarine waters. These processes displayed similar direct temperature and substrate concentration dependence within the natural range of these variables. Thus, if more DMS were to be produced, more would likely be consumed as well. 
These interactions would tend to maintain the concentration of DMS within a narrow range. It may be premature to extend these conclusions to oceanic systems in general since relatively little experimental work has been done, especially in polar regions. However, interactions such as those described here may help to explain why regionally averaged DMS concentrations vary by only a factor of 2 or 3 from the highly productive upwelling zones to the oligotrophic oceans (Andreae 1990). Despite relatively low (2 to $5 \mathrm{nM}$ ) average DMS concentrations in the ocean, much higher concentrations have been observed in frontal regions and in blooms of certain phytoplankton (Barnard et al. 1984, Holligan et al. 1987, Gibson et al. 1990). Undoubtedly, certain factors or conditions, which remain poorly understood, must upset the balance between DMS production and consumption. resulting in substantially higher DMS concentrations.

The concentration of DMS is strongly influenced by biological processes including interactions between the phytoplankton, grazing organisms, and bacteria which metabolize both DMSP and DMS. For example, Dacey \& Wakeham (1986) showed that grazing by zooplankton on DMSP-containing phytoplankton stimulated DMS production. The exact mechanism responsible for increased DMS production was not determined, but could include enhanced degradation of intracellular DMSP by the phytoplankton or enhanced release of DMSP $_{\text {diss }}$ and subsequent bacterial degradation to DMS. The most likely mechanism for DMSP diss production, as for most labile DOC (dissolved organic carbon), is through sloppy feeding by herbivores and leaching from their fecal material (Jumars et al. 1989). Whether DMS accumulates to any significant extent may depend on the relative capacities of microorganisms in the water to utilize DMSP diss and DMS. The $V_{\max }$ or the maximum rate of a given reaction in a water sample, is an estimate of the amount of enzyme activity expressed in that water sample. If the $\mathrm{V}_{\max }$ for DMSP-lyase activity is greater than the $V_{\max }$ for DMS consumption, and sufficient DMSP is available, then DMS consumption will become saturated and the DMS concentration would increase. The senescence phase of blooms might be a case where a large quantity of DMSP is released into the water. This could explain why Nguyen et al. (1988) observed substantial DMS accumulations only during the decline of phytoplankton blooms in flowthrough microcosms. Eventually, a build-up in DMS may cause an increase in the DMS consuming organisms (or enzyme systems) and DMS would then decline. Physical factors such as advection or exchange with the atmosphere could also remove DMS. Knowledge of the relative values of $V_{\max }$ as well as other kinetic parameters (e.g. half-saturation constants), for DMS production and consumption would be extremely useful in modeling the dynamics of these compounds in seawater The results from the present study suggest that, with the proper approach, these kinetic parameters can be estimated. The competition between the lyase pathway and the alternative degradation pathway(s) for DMSP diss needs to be considered as well.

It is becoming clear that only a small fraction of the total DMSP-sulfur in seawater is likely to escape to the atmosphere. The present results suggest that if all of the algal DMSP which is turned over in a given period

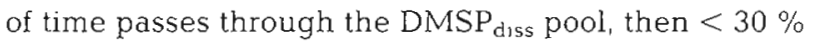
of this sulfur will be converted to DMS (based on Table 1 and the discussion above). Of the DMS formed, only $10 \%$ or so $(3 \%$ of the original DMSP-S) is likely to escape to the atmosphere because the biological turnover time of DMS in surface seawater is generally 10 times faster than DMS exchange with the atmosphere (Kiene \& Bates 1990). More DMS would escape if DMS were produced directly by phytoplankton and DMSP dss was not formed, but even with this scenario, $90 \%$ of the DMS is likely to be consumed within the water column (Kiene \& Bates 1990). Further work will be needed to compare the relative sources and sinks for DMSP and DMS in different regions of the ocean. The possibility that only a small percentage of the total dimethyl sulfur in seawater escapes to the atmosphere is interesting because it suggests that a small perturbation in the cycling of DMSP and DMS could significantly alter the amount of DMS ultimately emitted to the atmosphere.

Acknowledgements. Support for this research was provided by the National Science Foundation Grant OCE-88-17442 and the University of Georgia Marine Institute. The excellent technical assistance of Donna Summers is appreciated.

\section{LITERATURE CITED}

Andreae, M. O. (1986). The ocean as a source of atmospheric sulphur compounds. In: Buat-Menard, P. (ed.) The role of air-sea exchange in geochemical cycling. D. Reidel Publishing Co., Dordrecht, p. 331-362

Andreae, M. O. (1990). Ocean-atmosphere interactions in the global biogeochemical sulfur cycle. Mar Chem. 30: 1-29

Andreae, M. O., Barnard, W. R. (1983). Determination of trace quantities of dimethyl sulfide in aqueous solutions. Anal. Chem. 55: 608-61.2

Andreae, M. O., Barnard, W. R. (1984). The marine chemistry of dimethylsulfide. Mar Chem. 14:267-279

Barnard, W. R., Andreae, M. O., Iverson, R. L. (1984). Dimethyl sulfide and Phaeocystis pouchetii in the southeastern Bering Sea. Cont. Shelf. Res. 3: 103-113

Bates, T S., Charlson, R. J., Gammon, R. H. (1987). Evidence for the climatic role of marine biogenic sulphur Nature, Lond. 329: 319-321

Brimblecombe, P., Shooter, D. (1986). Photo-oxidation of dimethylsulphide in aqueous solution. Mar Chem. 19: 343-353

Brinkman, F. E., Olsen, G. J., Thayer, J. S. (1985). Biological 
mediation of marine metal cycles: the case of methyl iodide. In: Sigleo, A. C., Hattori, A. (eds.) Marine and estuarine geochemistry. Lewis Publishers, Chelsa, Michigan, p. 227-238

Cantoni, G. L., Anderson, D. G. (1956). Enzymatic cleavage of dimethylpropiothetin by Polysiphonia leaves. J. biol. Chem. 222: 171-177

Charlson, R. J., Lovelock, J. E., Andreae, M. O., Warren, S. G. (1987). Oceanic phytoplankton, atmospheric sulfur, cloud albedo and climate. Nature, Lond. 326: 655-661

Dacey, J. W. H., Blough, N. (1987). Hydroxide decomposition of DMSP to form DMS. Geophys. Res. Lett. 14: 1246-1249

Dacey, J. W. H., Wakeham, S. G. (1986). Oceanic dimethylsulfide: production during zooplankton grazing on phytoplankton. Science 233: 1314-1316

Erickson, D. J. (1990). Global ocean-to-atmosphere dimethyl sulfide flux. J. geophys. Res. 95: 7543-7552

Gibson, J. A. E., Garrick, R. C., Burton, H. R., McTaggart, A. R. (1990). Dimethylsulfide and the alga Phaeocystis pouchetii in antarctic coastal waters. Mar Biol. 104: 339-346

Holligan, P. M., Turner, S. M., Liss, P. S. (1987). Measurements of dimethyl sulphide in frontal regions. Cont. Shelf Res. 7. 213-224

Ishida, Y (1968). Physiological studies on the evolution of dimethylsulfide. Mem. Coll. Agric. Kyoto Univ. 94: 47-82

Iverson, R. L., Nearhoof, F. L., Andreae, M. O. (1989). Production of dimethylsulfonium propionate and dimethylsulfide by phytoplankton in estuarine and coastal waters. Limnol. Oceanogr 34: 53-67

Jumars, P. A., Penry, D. L., Baross, J. A., Perry, M. J., Frost, B. W. (1989). Closing the microbial loop: dissolved carbon pathway to heterotrophic bacteria from incomplete ingestion, digestion and absorption in animals. Deep Sea Res. 36: $483-495$

Kanagawa, T., Kelly, D. P. (1986). Breakdown of dimethyl sulphide by mixed cultures and by Thiobacillus thioparus. FEMS Microbiol. Lett 34: 13-19

Karsten, U., Wienke, C., Kirst, G. O. (1990). The B-dimethylsulfoniopropionate (DMSP) content of macroalgae from Antarctic and Southern Chile. Botanica mar 33: 143-146

Keller, M. D. Bellows, W. K., Guillard, R. R. L. (1989). Dimethyl sulfide production in marine phytoplankton. In: Saltzman, E., Cooper, W J. (eds.) Biogenic sulfur in the environment. 393. Am. Chem. Soc., Washington, D.C., p. $167-182$

Kiene, R. P. (in press). Microbial cycling of organosulfur gases in marine and freshwater environments. Mitt. int. Verein. theor angew. Limnol. 23

Kiene, R. P. (1990). Dimethyl sulfide production from dimethylsulfoniopropionate in coastal seawater samples and bacterial cultures. Appl. environ. Microbiol. 56: 3292-3297

Kiene, R. P., Bates, T S. (1990). Biological removal of dimethyl sulfide from seawater. Nature, Lond. 345: 702-705

Kiene, R. P., Taylor, B. F. (1988). Demethylation of dimethylsulfoniopropionate and production of thiols in anoxic marine sediments. Appl. environ. Microbiol. 54: $2208-2212$

This article was submitted to the editor
Leck, C., Larsson, U., Bagender, L. E., Johansson, S., Hajdu, S. (1990). Dimethylsulfide in the Baltic Sea: annual variability in relation to biological activity. J. geophys. Res. $95 \mathrm{C} 3$ : 3353-3364

Ledyard, K., Dacey, J. W H. (1990). Production of DMS from DMSP by a marine bacterium. EOS 71. 104

Lee, C., Wakeham, S. G. (1988). Organic matter in seawater: Biogeochemical processes. Chem. Oceanogr 9:1-51

Mopper, K., Taylor, B. F. (1986). Biogeochemical cycling of sulfur: thiols in coastal marine sediments. In: Sohn, $M$. J. (ed.) Organic marine geochemistry, Vol. 305. Am. Chem. Soc., Washington, D.C., p. 324-339

Nguyen, B. C., Belviso, S., Mihalopoulos, N. (1988). Dimethyl sulfide production during natural phytoplankton blooms. Mar. Chem. 24: 133-141

Reed, R. H. (1983). Measurement and osmotic significance of $\beta$-dimethylsulfoniopropionate in marine algae. Mar. Biol. Lett. 4: 173-181

SAS Institute Inc. (1985). SAS/STAT Guide for personal computers. Version 6 edition. SAS Institute Inc., Cary, NC

Shieh, H. S. (1966). Further studies on the oxidation of betaine by a marine bacterium. Achromobacter cholinophagum. Can. J. Microbiol. 12: 299-302

Suylen, G. M. H., Stefess, G. C., Kuenen, J. G. (1986). Chemolithotrophic potential of a Hyphomicrobium species, capable of growth on methylated sulfur compounds. Arch. Microbiol 146: 192-198

Taylor, B. F., Gilchrist, D. C. (1991). Degradation of methiolpropionate, an intermediate in the metabolism of dimethyl-sulfoniopropionate (DMSP), by marine bacteria. Abstract Q-86, American Society for Microbiology, p. 290

Turner, S. M., Malin, G. Bagander, L. E., Leck, C. (1990). Interlaboratory calibration and sample analysis of dimethylsulphide in water. Mar Chem. 29:47-62

Turner, S. M., Malin, G., Liss, P. S. (1988). The seasonal variation of dimethyl sulfide and dimethylsulfoniopropionate concentrations in nearshore waters. Limnol. Oceanogr. 33: $364-375$

Turner, S. M., Malin, G., Liss, P. S. (1989). Dimethyl sulfide and (dimethylsulfonio)propionate in European coastal and shelf waters. In: Saltzman, E. S., Cooper, W. J. (eds.) Biogenic sulfur in the environment. 393. Am. Chem. Soc., Washington, D.C., p. $183-200$

Vairavamurthy, A., Andreae, M. O., Iverson, R. L. (1985). Biosynthesis of dimethylsulfide and dimethylpropiothetin by Hymenomonas carterae in relation to sulfur source. Limnol. Oceanogr. 30: 59-70

Wakeham, S. G., Dacey, J. W. H. (1989). Biogeochemical cycling of dimethyl sulfide in marine environments. In: Saltzman, E. S., Cooper, W. J. (eds.) Biogenic sulfur in the environment. 393. Am. Chem. Soc., Washington, D.C., p. $152-166$

Wakeham, S. G., Howes, B. L., Dacey, J. W. H. (1987). Biogeochemistry of dimethylsulfide in a seasonally stratified coastal salt pond. Geochim. Cosmochim. Acta 51: 1675-1684

White, R. H. (1982). Analysis of dimethyl sulfonium compounds in marine algae. J. mar Res. 40: 529-535

Manuscript first received: April 17, 1991

Revised version accepted: June 21,1991 